\title{
Impact of cutting parameters on machining of Ti-6Al-4V alloy: an experimental and FEM approach
}

\author{
Kathirvel Gobivel $^{1, *}$, Krishnaraju Srinivasaraju Vijaysekar ${ }^{2}$, and Gopalakrishnan Prabhakaran $^{1}$ \\ ${ }^{1}$ Department of Mechanical Engineering, KCG College of Technology, Karapakkam 600 097, Tamilnadu, India \\ 2 Department of Mechanical Engineering, Sri Sivasubramaniya Nadar College of Engineering, Kalavakkam 603 110, Tamilnadu, India
}

Received: 10 January 2021 / Accepted: 7 April 2021

\begin{abstract}
Titanium alloys are used as an aerospace material due to their inherent properties such as high strength to weight ratio, corrosion, and fracture resistance. However, the low conductivity and reactivity towards plastic deformation causes these materials to be difficult to cut category. The prediction of various parameters like chip formation and actual cutting forces are important factors for better machinability which involves lot of resources. To overcome such issues, this work proposes three-dimensional FE approach to simulate the machinability behavior of Ti-6Al-4V especially on conventional turning. The impact of cutting speed and feed rate on the cutting force, thrust force, feed force and surface roughness were analyzed experimentally for various conditions. The predicted machining forces showed strong correlation with the experimental results and the effective von mises stress were examined.
\end{abstract}

Keywords: Ti-6Al-4V alloy / turning / 3D-FEM / cutting forces / von-mises stress / roughness

\section{Introduction}

The use of titanium-based alloys in aerospace, bio medical and nuclear equipment's are known due to the attractive properties of physical as well as metallurgical characteristics. While conventional turning of these materials causes rapid tool wear due to high temperature on the cutting edge. To avoid such issues the finite element modeling and machining of these material under hot condition [1] was carried out and observed that reduction of cutting forces with increase in cutting speed. Also, the stress-strain response was recorded and compared with room temperature environment. Rao et al. [2] investigate the experimental and numerical modeling to understand the machining behavior using perforated PCD insert under MQL environment and found improvement on machined surface, reduction in cutting temperature and vibrations.

Shao et al. [3] employed thermodynamically constitutive equation in $\mathrm{FE}$ approach to establish the machining results which showed the reality of cutting temperature and compared the experimental and predicted tool wear depth. Song et al. [4] studied 2D FE model on Ti-6Al-4V by multi-step, pre-stress multi-step showed increase in chip segmentation and concluded effective increase in compressive residual stress. Sushinder et al. [5] investigated drilling

\footnotetext{
* e-mail: gobivel@gmail.com
}

studies on titanium alloy to find the effects of thrust force, torque chip characteristics. Thermal softening nature dominated at higher cutting speed moreover reduced the thrust force and torque. Bajpai et al. [6] conducted threedimensional milling process on Ti-6Al-4V and observed the primary chip formation mechanisms along with the vonmises stress distribution. The maximum stress was $1518 \mathrm{MPa}$ found near to rubbing area of tool rake face and the curl type of chip formation was formed during simulation.

Chen et al. [7] investigated the impact of constitutive material models on cutting simulation of $\mathrm{Ti}$ alloys, observed that the stress and damage evolution by three different constitutive models were well correlated with each other and the predicted results on cutting forces and chip formation were close agreement with experimental results. Pradhan et al. [8] studied the machining characteristics of Ti6Al-4V and compared the machining forces with FE simulations and obtained the better machining performance at the cutting speed of $112 \mathrm{~m} / \mathrm{min}$. Also revealed that chip segmentation occurred due to fracture and plastic strain. FE studies on turning of Ti-6Al-4V to understand the effect of tool insert texturing $[9,10]$ on cutting force, temperature, chips morphology and observed that curled chip was formed during non-textured tool. Sahoo et al. [11] conducted hybrid modeling approach and found that the trends of predicted and experimental cutting force showed closer agreement with small variations. Shi et al. [12] 


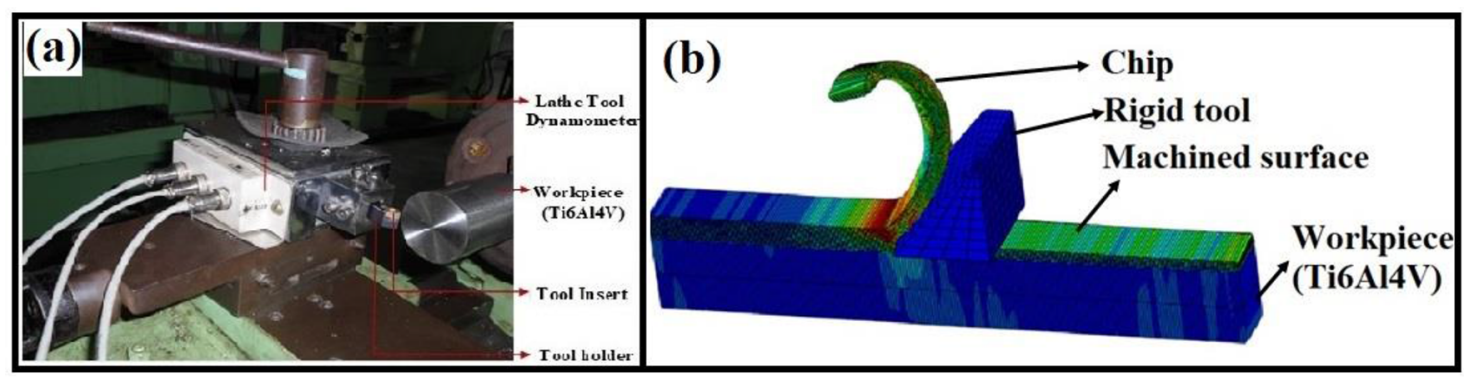

Fig. 1. Machining process (a) Experimental setup (b) FE simulation.

studied hybrid approach on CFD and FEM to simulate cryogenic machining to evaluate cooling effect on tool temperature and tool wear.

From the literatures, very few 3 -D modeling on Ti alloy were performed and a greater number of works on 2-D finite element method were carried out for the simulation of Ti-6Al-4V to predict the cutting forces, temperature, chip analysis and tool morphology. Despite the fact that the 2-D models allow for a good representation, since practical machining is not a two-dimensional method, this present work develop the 3-D finite element model for the turning of Ti- $6 \mathrm{Al}-4 \mathrm{~V}$ to predict the cutting force, thrust force and feed force for varied cutting speed and feed rates at constant depth of cut and the surface roughness were measured experimentally. The effect of von-mises stress were analyzed for various cutting conditions. The main benefit of three-dimensional finite element approach considered for accurate prediction of machining forces specially to analyze thrust force and feed force.

\section{Methods}

\subsection{Experimental work}

Turning experiment was performed on the conventional lathe using TiAlN coated carbide insert under dry cutting environment. The tool insert geometry was $10^{\circ}$ rake and $7^{\circ}$ clearance angle mounted on the tool holder. This TiAlN coated insert was chosen because of low cost compared to $\mathrm{PCD}$ and $\mathrm{CBN}$ inserts and optimized tool geometries which have the tendency to machining hard to cut materials. The work material which is in the form of cylindrical rod having $40 \mathrm{~mm}$ diameter and $150 \mathrm{~mm}$ length. Figure 1a showed the machining set up of Ti-6Al-4V with TiAlN carbide coated insert mounted on lathe tool dynamometer and the range of cutting speed and feed rate was chosen based on the preliminary experimental trial-and-error method and literature survey. The cutting speed and feed rate range between $18-61 \mathrm{~m} / \mathrm{min}$ and $0.06-0.09 \mathrm{~mm} / \mathrm{rev}$ at constant depth of cut $0.5 \mathrm{~mm}$. The machining forces were recorded by dynamometer based on strain gauge with in-built data acquisition software which the time versus forces were plotted. The surface quality was measured on the machined surface using Surftest SJ-210 for all the cutting conditions. Chips formed from the various cutting parameters were collected and analyzed.
Table 1. J-C Material Model parameter for Ti-6Al-4V (Lee and Lin [14]).

\begin{tabular}{lllll}
\hline $\mathrm{A}(\mathrm{MPa})$ & $\mathrm{B}$ & $\mathrm{n}$ & $\mathrm{C}$ & $\mathrm{m}$ \\
\hline 782.7 & 498.4 & 0.28 & 0.028 & 1.0 \\
\hline
\end{tabular}

\subsection{Simulation}

The 3-D FE model has been developed using ABAQUS/ Explicit to simulate the turning process of Ti- $6 \mathrm{Al}-4 \mathrm{~V}$ as shown in Figure 1b. The numerical simulation consists of work and tool geometry, work tool interactions, mechanical properties of work and tool, boundary conditions and chip separation criteria. The work material was defined as an elasto-plastic which modeled as rectangular block to assign its mechanical properties. The tool geometry was modeled as like those used in experimental trails. The Johnson Cook material constitutive equation was used to understand the plastic behavior which describes strain, strain rates and temperature dependent properties as shown in the equation (1). Table 1 showed the material constants of Ti-6Al-4V for the JC equation [13] used in this work. Left extreme and bottom of the work piece was constrained using ENCASTRE option and the tool was moved in positive direction. ALE method was adopted and the mesh refinement was done on the iterative convergence procedure based on trial and error method

$$
\begin{aligned}
\sigma= & {\left[A+B \varepsilon^{n}\right]\left[1+C \ln \left(\varepsilon^{\prime} / \varepsilon_{o}^{\prime}\right)\right] } \\
& \times\left[1-\left\{\left(T-T_{\text {room }}\right) /\left(T_{\text {melt }}-T_{\text {room }}\right)\right\}^{m}\right] .
\end{aligned}
$$

\section{Result and discussion}

\subsection{Cutting force}

Figure 2 showed the comparison of cutting force predictions of the FE model and experimental results at different cutting speed and feed rates. Table 2 showed the $\mathrm{FE}$ and experimental values of cutting force and its error percentage. From Figure 2a the experimental cutting force decreased with the increase in cutting speed. At cutting speed $18.8 \mathrm{~m} / \mathrm{min}$ the error $3.53 \%$ produced closest correlation with average experimental results. The similar trend was observed at feed $=0.079 \mathrm{~mm} / \mathrm{rev}$ experimentally where the cutting forces decreased with increase in cutting 

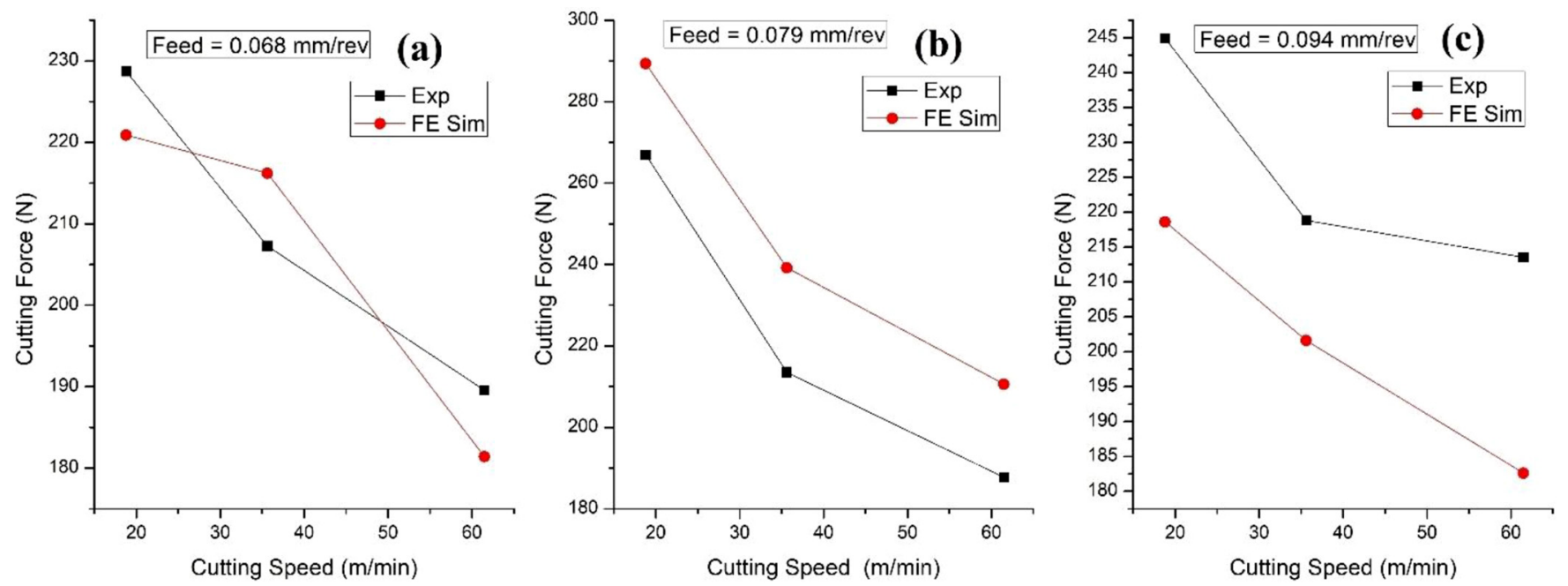

Fig. 2. Comparison of Exp and FE cutting forces at different feed rate.

Table 2. Cutting force values and error $\%$.

\begin{tabular}{llccc}
\hline Feed $(\mathrm{mm} / \mathrm{rev}) /$ Cutting speed $(\mathrm{m} / \mathrm{min})$ & 18.8 & 35.62 & 61.49 \\
\hline \multirow{4}{*}{0.068} & FE value & 220.9 & 216.2 & 181.4 \\
& Exp value & 228.7 & 207.26 & 189.56 \\
& Error & $3.53 \%$ & $-4.13 \%$ & $4.49 \%$ \\
0.079 & FE value & 289.33 & 239.2 & 210.6 \\
& Exp value & 266.97 & 213.52 & 187.73 \\
& Error & $-7.72 \%$ & $-10.73 \%$ & $-10.85 \%$ \\
0.094 & FE value & 218.62 & 201.6 & 182.6 \\
& Exp value & 244.91 & 218.83 & 213.52 \\
& Error & $12.02 \%$ & $8.54 \%$ & $16.93 \%$ \\
\hline
\end{tabular}

speed while the FE prediction yielded the next best results when compared with the actual machining results as shown in Figure 2b. At feed $=0.094 \mathrm{~mm} / \mathrm{rev}$, the trend of experimental results was similar, but the FE results were moderately compared to the actual conditions as shown in Figure 2c. Increased strain hardening effect of titanium alloy at higher values of feed rate and cutting speed attributed to moderate predictions of cutting force because of low range of strain rate taken into computation of flow stress data [15].

\subsection{Thrust force}

The comparison of FE predicted model and experimental results on thrust forces for different cutting speed and feed rate as shown in Figure 3. Table 3 showed the FE and experimental values of thrust force and its error percentage. In general, the thrust force reflects the interaction of machined surface and clearance angle in which the similar trend was followed in the FE predictions too. When increasing the cutting speed, the tool shear angle increases, and a thrust force reduces due to the reduction in chip-tool contact length. At feed rate of $0.068 \mathrm{~mm} / \mathrm{rev}$, it was found that -3 to $-12 \%$ deviation as shown in Figure 3 a gives the closer agreement with experimental results. However, the deviation of -2 to $-18 \%$ at the feed rate of $0.079 \mathrm{~mm} / \mathrm{rev}$ and $-7 \%$ to $-19 \%$ error at feed rate of $0.094 \mathrm{~mm} / \mathrm{rev}$ was observed as shown in Figure $3 \mathrm{~b}$ and c respectively. FE predictions of thrust force moderately closer with experimental results at higher feed rate conditions.

\subsection{Feed force}

FE predictions of feed force was compared with experimental results depicted in Figure 4. In general, feed forces are influenced by friction coefficient and frictional law, while the frictional value is higher, the feed force also higher. Coulomb friction was used in this work across all the cutting conditions to ensure its uniformity. Table 4 showed the FE and experimental values of feed force and its error percentage. The prediction of FE model for feed forces showed less accurate than cutting and thrust forces across the cutting conditions. The deviation of $-7 \%$ to $-24 \%$ and $-7 \%$ to $-15 \%$ as shown in Figure $4 \mathrm{a}$ and $\mathrm{b}$ were observed 

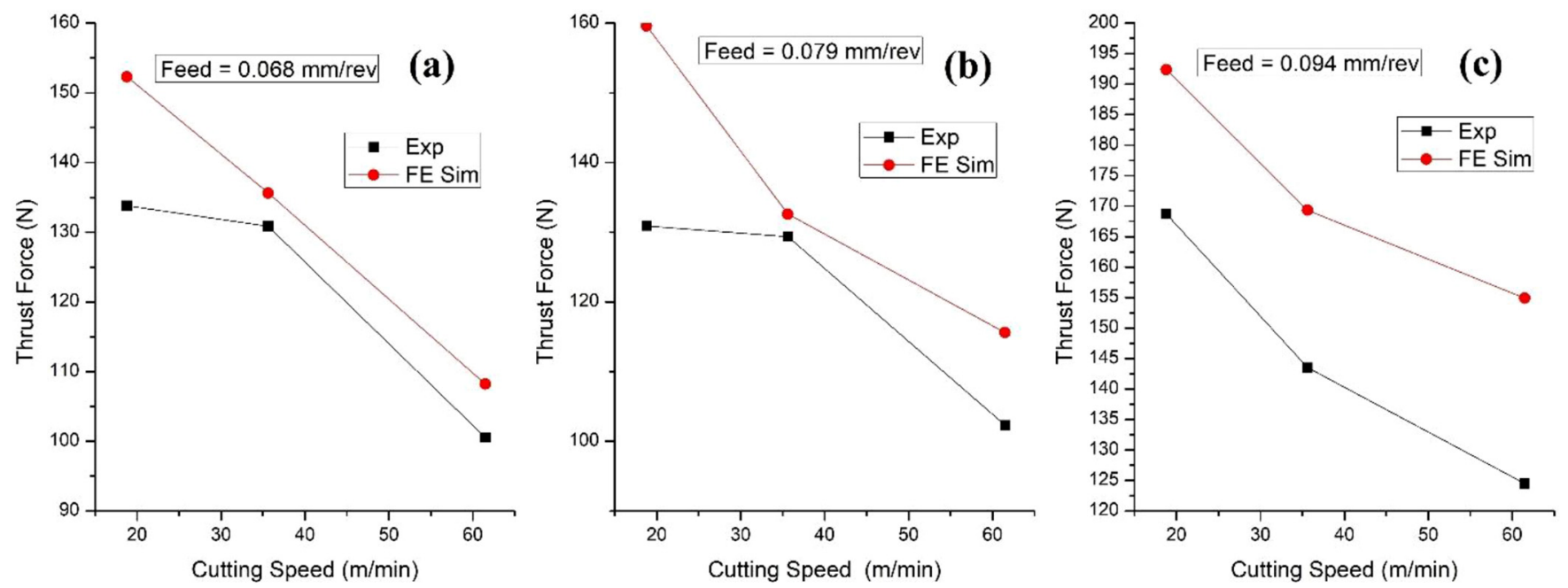

Fig. 3. Comparison of Exp and FE thrust forces at different feed rate.

Table 3. Thrust force values and error $\%$.

\begin{tabular}{clllc}
\hline Feed $(\mathrm{mm} / \mathrm{rev}) /$ Cutting speed $(\mathrm{m} / \mathrm{min})$ & 18.8 & 35.62 & 61.49 \\
\hline \multirow{4}{*}{0.068} & FE value & 152.31 & 135.62 & 108.22 \\
& Exp value & 133.8 & 130.87 & 100.5 \\
& Error & $-12.152 \%$ & $-3.502 \%$ & $-7.133 \%$ \\
0.079 & FE value & 159.6 & 132.6 & 115.6 \\
& Exp value & 130.88 & 129.37 & 102.31 \\
& Error & $-17.995 \%$ & $-2.435 \%$ & $-11.496 \%$ \\
0.094 & FE value & 192.4 & 169.32 & 154.9 \\
& Exp value & 168.72 & 143.5 & 124.48 \\
& Error & $-12.307 \%$ & $-15.249 \%$ & $-19.638 \%$ \\
\hline
\end{tabular}

which is moderate closer agreement with actual machining conditions. But the feed rate $0.094 \mathrm{~mm} / \mathrm{rev}$ showed the error of -8 to $-45 \%$ as shown in Figure $4 \mathrm{c}$ deviation was below par and it was affected by all the constants of Johnsons Cook.

\subsection{Stress distribution}

Figure 5 shows the predicted von mises stress distribution with the FE models for various cutting conditions. It reveals the maximum stress distribution at the distortion zone where the work and tool material in contact. At feed rate $0.068 \mathrm{~mm} / \mathrm{rev}$, the stress distribution show good consistency across the cutting speed with the ranges from 178 to $1093 \mathrm{MPa}$ as shown in Figure 5a-c. At feed $0.079 \mathrm{~mm} / \mathrm{rev}$, the similar stress pattern ranges from 177 to $1099 \mathrm{MPa}$ predicted across the cutting speed as shown in
Figure $5 \mathrm{~d}-\mathrm{f}$. However, at the feed rate of $0.094 \mathrm{~mm} / \mathrm{rev}$ marginal decreaseof von mises stress predicted at the range of $159-987 \mathrm{MPa}$ as shown in Figure $5 \mathrm{~g}-\mathrm{i}$.

\subsection{Surface roughness}

Surface roughness $\left(\mathrm{R}_{\mathrm{a}}\right)$ is one of the important parameters to analyses the quality of the machined surface quantitatively. The graphical comparison of $\mathrm{R}_{\mathrm{a}}$ with respect to different cutting speed and feed rate was evaluated. Figure 6 depicts that the roughness value gradually decreased with increase in cutting speed at feed rate $=$ $0.068 \mathrm{~mm} / \mathrm{rev}$ due to low ploughing effect. However, at feed rate $0.079 \& 0.094 \mathrm{~mm} / \mathrm{rev}$, the marginal increase in roughness was observed when cutting speed increases. It can be attributed to the tool advances along with its cutting path causes machine tool vibrations. 

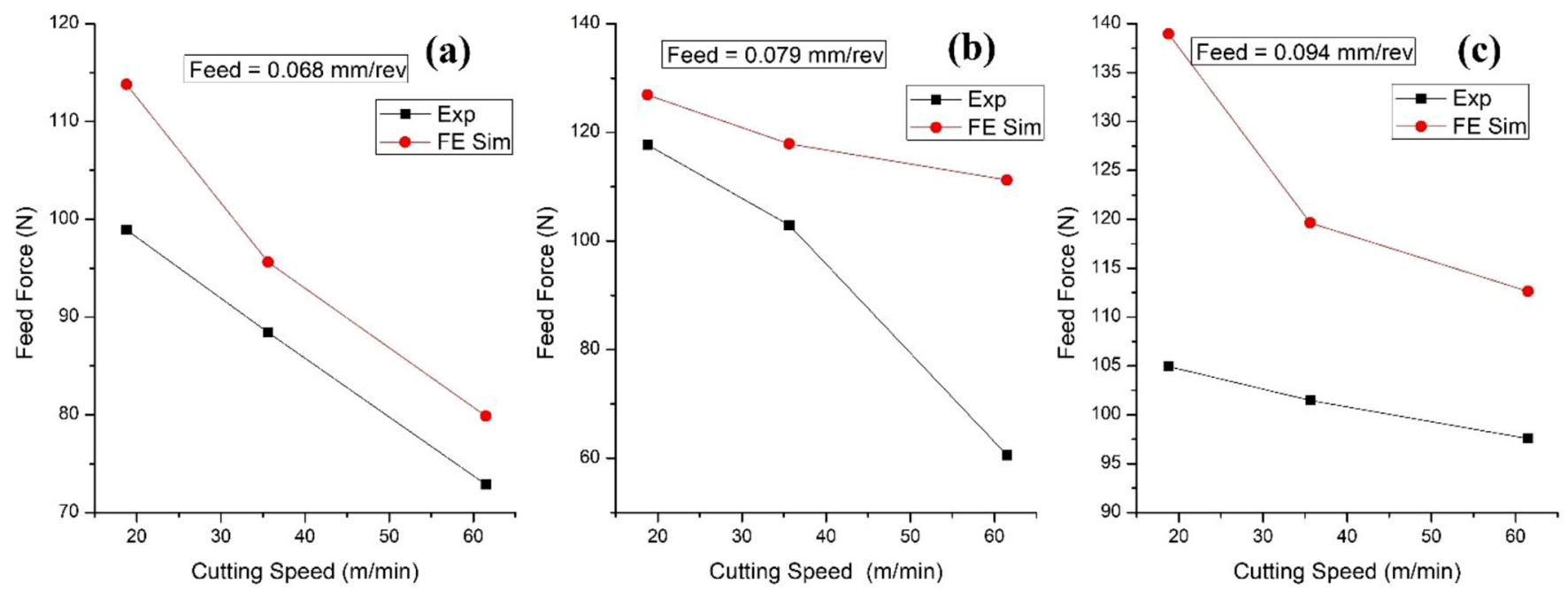

Fig. 4. Comparison of Exp and FE feed forces at different feed rate.

Table 4. Feed force values and error $\%$.

\begin{tabular}{llccc}
\hline Feed $(\mathrm{mm} / \mathrm{rev}) /$ Cutting speed $(\mathrm{m} / \mathrm{min})$ & 18.8 & 35.62 & 61.49 \\
\hline \multirow{4}{*}{0.068} & FE value & 113.78 & 95.61 & 79.86 \\
& Exp value & 98.9 & 88.41 & 72.85 \\
& Error & $-13.077 \%$ & $-7.530 \%$ & $-8.777 \%$ \\
0.079 & FE value & 126.9 & 117.89 & 111.23 \\
& Exp value & 117.67 & 102.93 & 60.58 \\
& Error & $-7.273 \%$ & $-12.689 \%$ & $-45.536 \%$ \\
0.094 & FE value & 138.95 & 119.63 & 112.63 \\
& Exp value & 104.93 & 101.48 & 97.57 \\
& Error & $-24.483 \%$ & $-15.171 \%$ & $-13.371 \%$ \\
\hline
\end{tabular}

\section{Conclusion}

The series of experimental trials was conducted to study the machinability behavior of Ti-6Al-4V and 3-D FE model was developed to predict the cutting force, thrust force and feed force. Von Mises stress distribution was observed and analyzed for the various cutting conditions. Also, the surface roughness was evaluated experimentally for different cutting speed and feed rate. The following conclusions are made:

- Predicted cutting forces showed closer agreement with experimental results especially in low cutting speed and feed rate. Similar trend was followed during the prediction of thrust forces however the FE model prediction over feed force showed lesser accuracy.

- Overall, the Von-Mises stress distribution was observed from the range of $177-1099 \mathrm{MPa}$ across the cutting conditions and marginal decrease in stress was found at higher cutting speed.
- Surface roughness $\left(\mathrm{R}_{\mathrm{a}}\right)$ was evaluated and found that gradual increase in roughness value when cutting speed increases at intermediate and high feed rate.

The 3-D FE model was developed found suitable to assess the machining forces and stress distribution of Ti-6Al-4V. Numerous trails can be carried out using 3D FE model for various cutting conditions which helps industry to select anoptimized condition for machining.

\section{Implications and influences}

Finite element modeling gained good popularity on machine tool industries for providing the detailed insights of the parameters like machining forces, chip analysis, tool wear studies, etc., for various conditions. The initial cost needs to be minimal which is a generic aim of any manufacturing sector and this can be possible by developing FE models to provide quick solutions. 

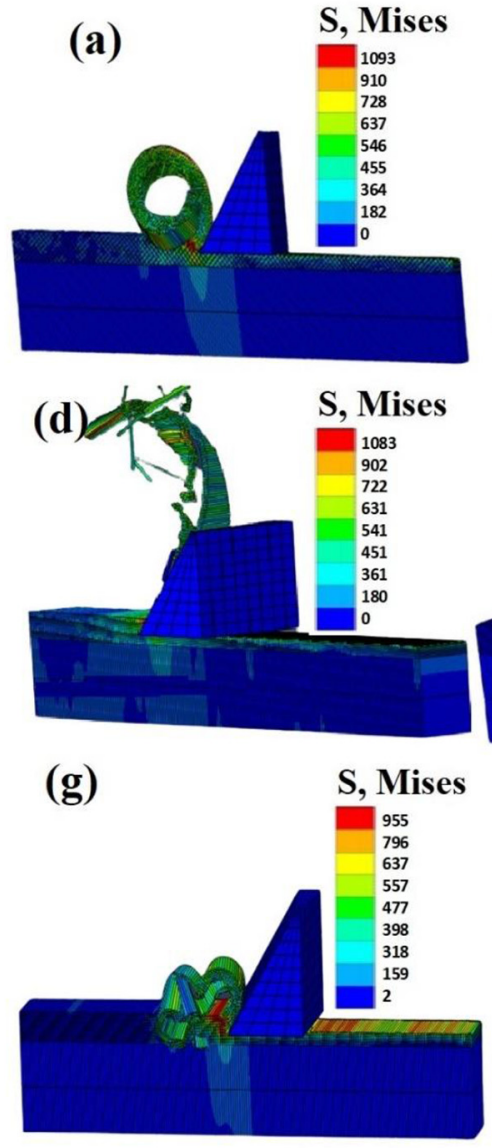

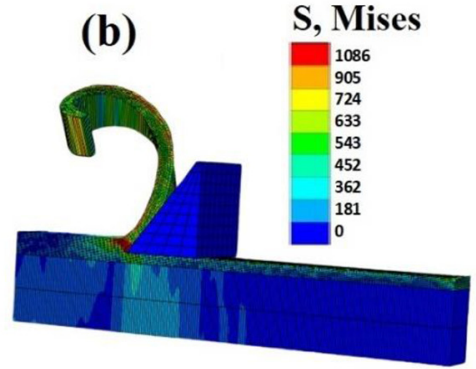

(e)

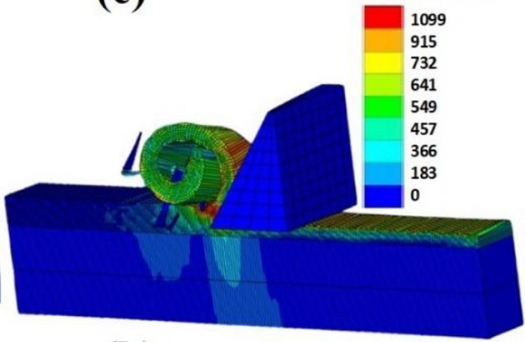

(h)

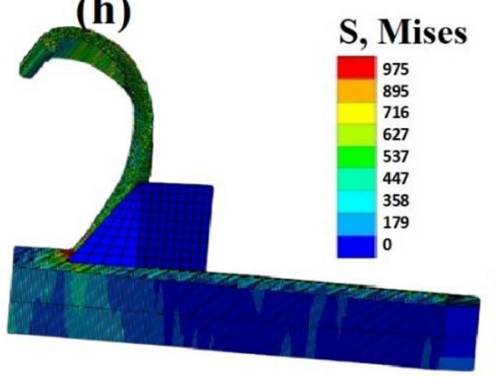

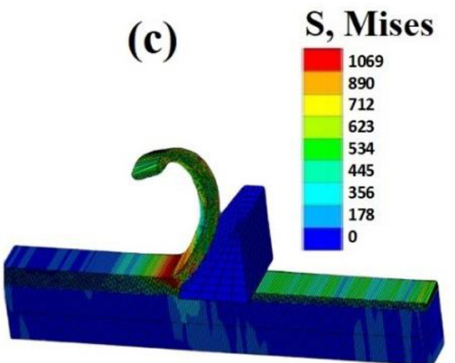

(f)

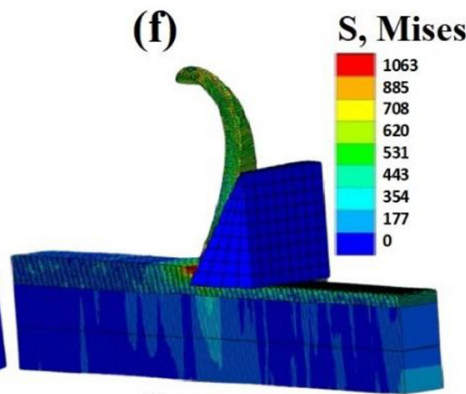

(i) S, Mises

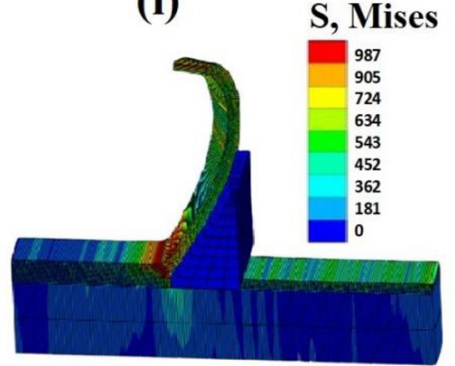

Fig. 5. von Mises stresses at various cutting speed and feed rate.

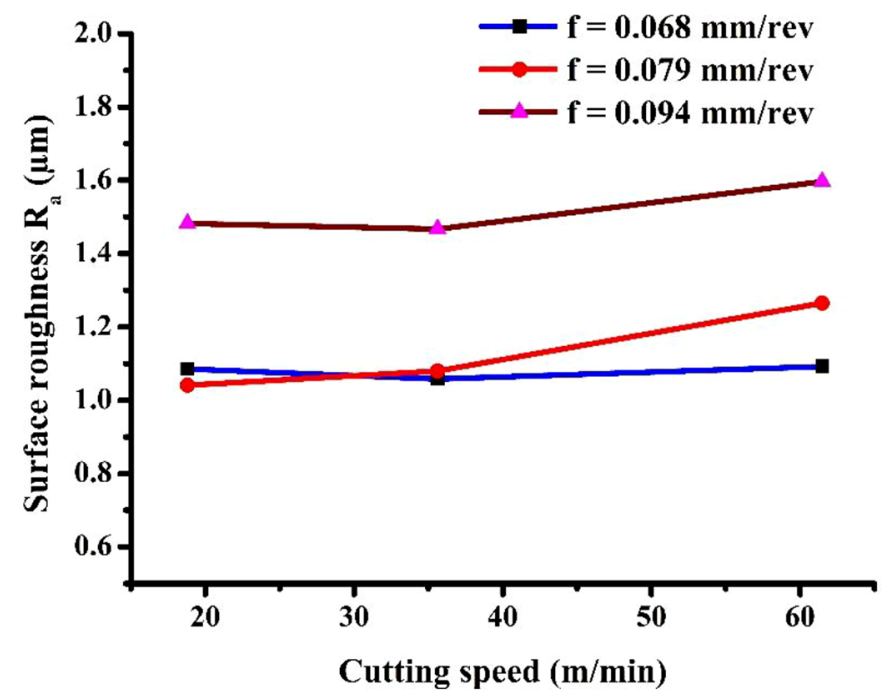

Fig. 6. Effect of cutting speed on surface roughness (Ra).

This work has an advantage to develop such FE models to conduct machining studies which negates the need for exhaustive experimental trials. Using the developed model, the machinability behavior can be studied even in higher cutting conditions and there is scope to improve numerical results accuracy by fine tuning mesh size, material model properties, etc., It can be extended further to analyze the chip morphology, tool wear, surface roughness models and correlate the analytical and numerical stress results.

\section{References}

1. A.K. Parida, K. Maity, Hot machining of Ti-6Al-4V: FE analysis and experimental validation, Sadhana-Acad. P. Eng. Sci. 44, 1-6 (2019)

2. C.M. Rao, S.S. Rao, M.A. Herbert, An experimental and numerical approach to study the performance of modified perforated cutting tools on machining of $\mathrm{Ti}-6 \mathrm{Al}-4 \mathrm{~V}$ alloy, Arab. J. Sci. Eng. 45, 1191-1206 (2020)

3. F. Shao, Z. Liu, Y. Wan, Z. Shi, Finite element simulation of machining of Ti-6Al-4V alloy with thermodynamical constitutive equation, Int. J. Adv. Manuf. Technol. 49, 431-439 (2010)

4. X. Song, A. Li, M. Lv, H. Lv, J. Zhao, Finite element simulation study on pre-stress multi-step cutting of Ti-6Al-4V titanium alloy, Int. J. Adv. Manuf. Technol. 104, 2761-2771 (2019)

5. K. Sushinder, P.R. Shivaram, S.B. Nivedh Kannaa, G. Nisarg, K.S. Vijay Sekar, Investigation of thrust forces, torque and chip microstructure during drilling of Ti-6Al-4V titanium alloy, Appl. Mech. Mater. 787, 431-436 (2015) 
6. V. Bajpai, I. Lee, H.W. Park, Finite element modeling of three-dimensional milling process of Ti-6Al-4V, Mater. Manuf. Proc. 29, 564-571 (2014)

7. G. Chen, L. Lianpeng, K. Zhihong, Q. Xuda, R. Chengzu, Influence of constitutive models on finite element simulation of chip formation in orthogonal cutting of Ti-6Al-4V alloy, Procedia Manuf. 33, 530-537 (2019)

8. S. Pradhan, S. Singh, C. Prakash, G. Krolczyk, A. Pramanik, C.I. Pruncu, Investigation of machining characteristics of hardto-machine Ti-6Al-4V-ELI alloy for biomedical applications, J. Mater. Res. Technol. 8, 4849-4862 (2019)

9. D. Arulkirubakaran, V. Senthilkumar, V. Kumawat, Effect of micro-textured tools on machining of Ti-6Al-4V alloy: an experimental and numerical approach, Int. J. Refract. Metals Hard Mater. 54, 165-177 (2016)

10. A.K. Parida, P.V. Rao, S. Ghosh, Performance of textured tool in turning of $\mathrm{Ti}-6 \mathrm{Al}-4 \mathrm{~V}$ alloy: numerical analysis and experimental validation, J. Braz. Soc. Mech. Sci. Eng. 42, 255 (2020)
11. P. Sahoo, T. Pratap, K. Patra, A hybrid modelling approach towards prediction of cutting forces in micro end milling of Ti-6Al-4V titanium alloy, Int. J. Mech. Sci. 150, 495-509 (2019)

12. B. Shi, A. Elsayed, A. Damir, H. Attia, R. M'Saoubi, A hybrid modeling approach for characterization and simulation of cryogenic machining of Ti-6Al-4V alloy, ASME J. Manuf. Sci. Eng. 141, 021021 (2019)

13. G.R. Johnson, W.H. Cook, Constitutive model and data for metals subjected to large strains, high strain rates and high temperatures, in: Proceedings of the Seventh International Symposium on Ballistics, 1983, The Hague, pp. 541-547

14. W.S. Lee, C.F. Lin, High-temperature deformation behaviour of Ti6A14V alloy evaluated by high strain-rate compression tests, J. Materi. Process. Technol. 75, 127-136 (1998)

15. K.S.V. Sekar, M.P. Kumar, Finite element simulations of Ti6Al4V titanium alloy machining to assess material model parameters of the Johnson-Cook constitutive equation, J. Braz. Soc. Mech. Sci. Eng. 33, 203-211 (2011)

Cite this article as: Kathirvel Gobivel, Krishnaraju Srinivasaraju Vijaysekar, Gopalakrishnan Prabhakaran, Impact of cutting parameters on machining of Ti-6Al-4V alloy: an experimental and FEM approach, Int. J. Simul. Multidisci. Des. Optim. 12, $2(2021)$ 